\title{
Bilirubin suppresses Th17 immunity in colitis by upregulating CD39
}

\author{
Maria Serena Longhi, ${ }^{1}$ Marta Vuerich, ${ }^{1}$ Alireza Kalbasi, ${ }^{1}$ Jessica E. Kenison, ${ }^{2}$ Ada Yeste, ${ }^{2}$ \\ Eva Csizmadia,' Byron Vaughn, ${ }^{1}$ Linda Feldbrugge, ${ }^{1}$ Shuji Mitsuhashi, ${ }^{1}$ Barbara Wegiel, ${ }^{3}$ \\ Leo Otterbein, ${ }^{3}$ Alan Moss, ${ }^{1}$ Francisco J. Quintana, ${ }^{2}$ and Simon C. Robson ${ }^{1}$ \\ 'Division of Gastroenterology, Department of Medicine, Beth Israel Deaconess Medical Center, Harvard Medical School, \\ Boston, Massachusetts, USA. 'Center for Neurologic Diseases, Brigham and Women's Hospital, Harvard Medical School, \\ Boston, Massachusetts, USA. ${ }^{3}$ Division of Transplantation, Department of Surgery, Beth Israel Deaconess Medical Center, \\ Harvard Medical School, Boston, Massachusetts, USA.
}

\begin{abstract}
Unconjugated bilirubin (UCB), a product of heme oxidation, has known immunosuppressant properties but the molecular mechanisms, other than antioxidant effects, remain largely unexplored. We note that UCB modulates T helper type 17 (Th17) immune responses, in a manner dependent upon heightened expression of CD39 ectonucleotidase. UCB has protective effects in experimental colitis, where it enhances recovery after injury and preferentially boosts IL-10 production by colonic intraepithelial CD4+ cells. In vitro, UCB confers immunoregulatory properties on human control Th17 cells, as reflected by increased levels of FOXP3 and CD39 with heightened cellular suppressor ability. Upregulation of CD39 by Th17 cells is dependent upon ligation of the aryl hydrocarbon receptor (AHR) by UCB. Genetic deletion of CD39, as in Entpd1 ${ }^{-1-}$ mice, or dysfunction of AHR, as in $A h^{d}$ mice, abrogates these UCB salutary effects in experimental colitis. However, in inflammatory bowel disease (IBD) samples, UCB fails to confer substantive immunosuppressive properties upon Th17 cells, because of decreased AHR levels under the conditions tested in vitro. Immunosuppressive effects of UCB are mediated by AHR resulting in CD39 upregulation by Th17. Boosting downstream effects of AHR via UCB or enhancing CD39-mediated ectoenzymatic activity might provide therapeutic options to address development of Th17 dysfunction in IBD.
\end{abstract}

Conflict of interest: The authors have declared that no conflict of interest exists.

Submitted: January 13, 2017

Accepted: March 23, 2017

Published: May 4, 2017

Reference information: JCI Insight. 2017;2(9):e92791. https:// doi.org/10.1172/ji.i.nsight.92791

\section{Introduction}

Unconjugated bilirubin (UCB) is a tetrapyrrole derived from the catabolism of heme with known antioxidant properties. High systemic concentrations of UCB in certain disease states are potentially injurious to the basal ganglia and neurons (1). However, physiological concentrations of this metabolite have immunomodulatory effects on antigen-presenting cells $(2,3)$ and effector cells $(2,4)$, ultimately favoring the expansion of FOXP3 $3^{+}$Tregs $(5,6)$. UCB immunomodulatory properties have been confirmed by in vivo experimental studies, as in the setting of islet cell transplantation $(6,7)$, experimental autoimmune encephalomyelitis (2), and in acute colitis induced by dextran sodium sulfate (DSS) (8).

Further support for the immunoregulatory effects of bilirubin derives from clinical observations indicating improvement of inflammatory/autoimmune conditions linked to high endogenous levels of this metabolite (9). Some patients with inflammatory bowel disease (IBD) (Crohn's disease and ulcerative colitis) develop primary sclerosing cholangitis (PSC), involving intra- and extrahepatic bile ducts. This complication is associated with increased blood levels of biliverdin, UCB, direct bilirubin, and urobilinogen. Jaundiced patients with concomitant ulcerative colitis and PSC seem to manifest milder or asymptomatic colitis when compared with patients with normal bilirubin levels (10). Similarly, patients with Gilbert syndrome, who have higher levels of UCB because of defective UDP glucuronosyl transferase 1 (UGT1A1), are less likely to develop IBD, further supporting the immunoprotective role of UCB in this condition (11, 12). Gunn rats with pronounced defects in UGTA1, an experimental model of Crigler-Najjar syndrome, are likewise relatively resistant to induction of experimental colitis (13).

$\mathrm{T}$ helper type 17 (Th17) cells are an effector immune subset (14) associated with intestinal inflammation (15). Th17 cells and the purinergic signaling are closely related, as extracellular ATP has been found to favor Th17 cell differentiation in the lamina propria (16). Th17 cells can also express CD39, an ectoenzyme that catalyzes the conversion of extracellular ATP and ADP into AMP, which is subsequently converted 
into immunosuppressive adenosine by the 5'-ectoenzyme CD73 (17). CD39 expression endows Th17 cells with immunosuppressive properties and promotes the transition to a less pathogenic phenotype (18).

Th17 cell immunity is also modulated upon engagement of aryl hydrocarbon receptor (AHR), a mediator of toxic or xenobiotic-mediated responses that belongs to the evolutionary bHLH-PAS protein family (19). Upon binding to exogenous ligands like environmental pollutants, dietary compounds, or endogenous metabolites, AHR mediates a variety of biological responses through the activation of the xenobioticmetabolizing enzyme cytochrome P4501 (CYP1) (20). AHR also plays a unique role in regulating adaptive cell immunity (21-23), including the CD39-dependent induction of Tregs (24). Alterations in the AHR pathway of activation are linked to chronic inflammation in IBD patients (25) and AHR deletion results in exacerbations of DSS-induced colitis $(26,27)$. Further, it has recently been shown that DSS-induced colitis is worsened upon reconstitution of RAG-2/IL2RG-deficient mice with T cells derived from $A h r^{d}$ mice (28) expressing an AHR molecule of reduced affinity (21).

Here we report, to our knowledge for the first time, that UCB immunosuppressive properties are mediated by CD39 expression induced in Th17 cells via ligand activation of AHR. Genetic alterations or impaired functionality of AHR can abrogate CD39 upregulation upon exposure to UCB in both experimental colitis and IBD-derived Th17 cells in human disease.

\section{Results}

$U C B$ ameliorates experimental colitis. Previous evidence had shown that UCB has immunomodulatory properties in inflammatory conditions in vivo $(2,6)$. We tested the effect of UCB administration on DSS-induced colitis during the induction and recovery phases of the disease, when the DSS treatment was replaced with standard drinking water. As depicted in Figure 1A, untreated and UCB-treated WT mice had similar disease activity indices up to and inclusive of day 9 when DSS treatment was discontinued. After day 10, UCB-treated mice stabilized at the same level of disease activity. This was in contrast to untreated mice, which exhibited further worsening of the disease. Measurement of colon length on day 12 showed increased colon length in UCB-treated compared with untreated animals (Figure 1B). Histological examination showed less mononuclear cell infiltration, decreased crypt distortion, and intraparenchymal edema in colonic sections from UCB-treated compared with untreated mice (Figure 1C). Further, UCB treatment decreased the proportion of IL-17-producing $\mathrm{CD}^{+} \mathrm{T}$ cells among lymphomononuclear cells obtained from spleen, mesenteric lymph nodes (MLNs), and lamina propria (Figure 1, D and E), and increased the proportion of $\mathrm{CD}^{+} \mathrm{IL}-10^{+}$cells among intraepithelial lymphocytes (IELs) (Figure 1, D and E). We also noted an increase in the proportion of $\mathrm{CD} 4^{+} \mathrm{IL}-17^{+} \mathrm{IL}-10^{+}$cells (Figure $1 \mathrm{E}$ ), suggesting that UCB favors the acquisition of immunoregulatory features by pathogenic Th17 cells. The mRNA levels of heme oxygenase-1 (HO-1; Hmox 1), the enzyme responsible for catalyzing the conversion of heme into biliverdin - the UCB precursor - were higher in spleen and MLN-derived mononuclear cells of mice subjected to DSS colitis when compared with DSS-untreated controls (Figure 1F), as reported previously and in keeping with the induction of HO-1 by stress (29-31).

Collectively, these data show that UCB ameliorates experimental colitis by stabilizing disease activity during the recovery phase and by restraining the proportion of effector IL-17-producing $\mathrm{CD} 4^{+} \mathrm{T}$ cells systemically and locally, in the site of tissue damage.

UCB boosts IL-10 and inhibits Th17 proliferation in healthy subjects. We next explored the effect of UCB on human Th17 cells that were derived from peripheral blood mononuclear cells (PBMCs) of healthy individuals upon conditioning of $\mathrm{CD}^{+} \mathrm{T}$ cells in the presence of IL-6, IL-1 $\beta$, and TGF- $\beta$. The average proportion of IL-17-producing CD4+ lymphocytes after 5-day polarization was $14 \pm 3.8 \%$, in agreement with our previous findings (18) and published literature (32). The proportion of IL-10-producing cells within the $\mathrm{CD} 4^{+} \mathrm{IL}-17^{+}$subset was then quantified (Figure 2A). Exposure of PBMC-derived Th17 cells to UCB resulted in an increase in the frequency of IL-10-producing cells (Figure 2A); this increase was mirrored by increases in the IL-10 mean fluorescence intensity (MFI) (Figure 2B) and mRNA levels (Figure 2C). UCB, however, did not alter other aspects of the Th17 cell phenotype, as reflected by levels of IL-17, RAR-related orphan receptor C (RORC), IL-23 receptor (IL-23R), and CCR6 expression (Figure 2D), but rather diminished the expression of IL-22 and IL-1 $\beta$, cytokines typically expressed by pathogenic Th17 cells (Figure 2E) $(33,34)$. UCB markedly abrogated Th17 cell proliferation (Figure $2 \mathrm{~F}$ ) without, however, increasing the cell apoptotic rate, as determined by the frequency of annexin $\mathrm{V}^{+}$cells (Figure $2 \mathrm{G}$ ). Thus, UCB modulates Th17 cell proinflammatory properties by boosting expression of IL-10 and markedly inhibiting cell proliferation. 
A

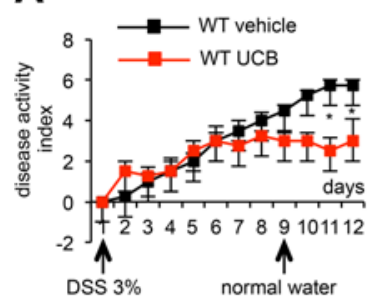

D
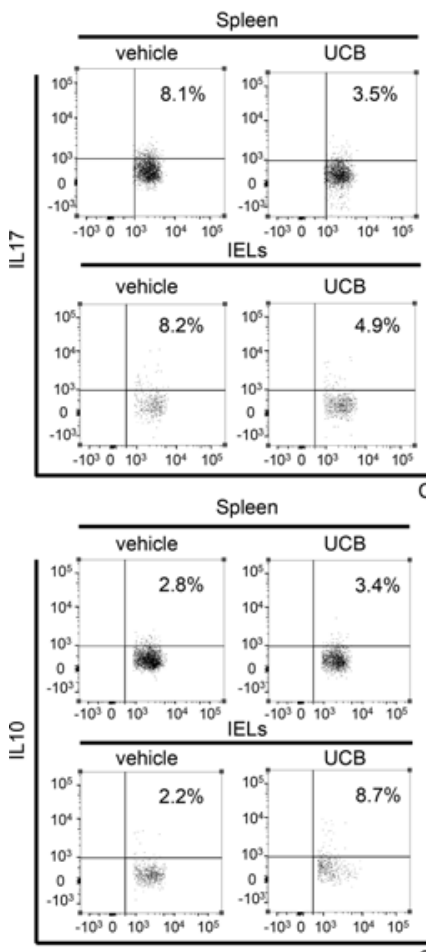

B
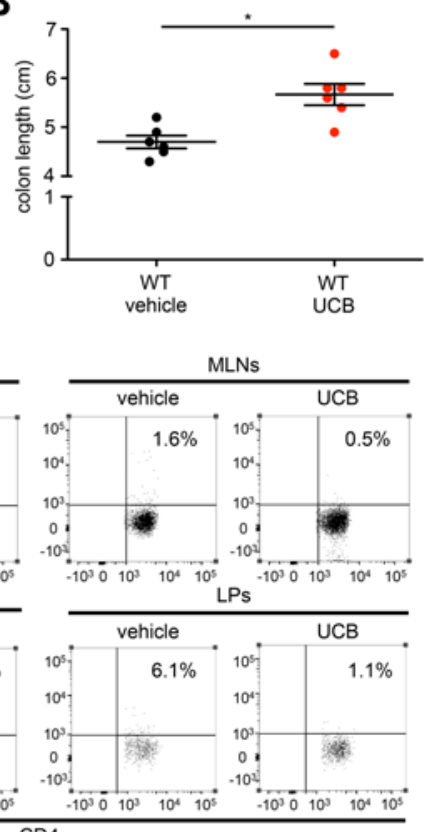

CD4

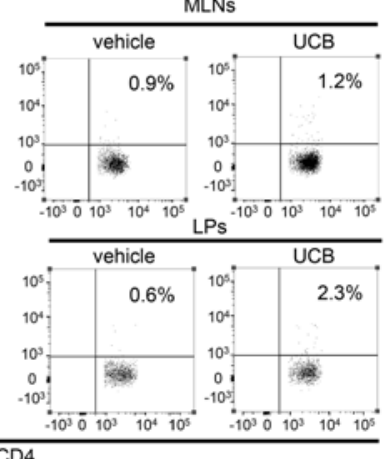

C
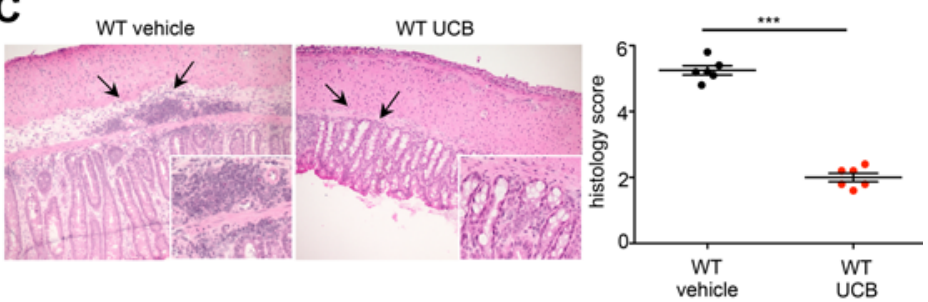

E

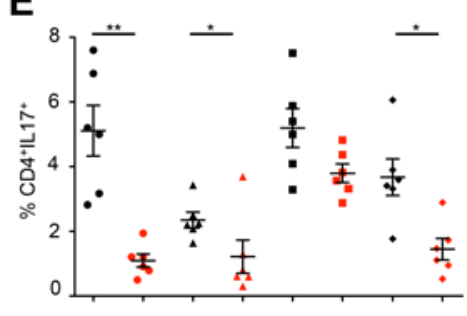

$\mathbf{F}$

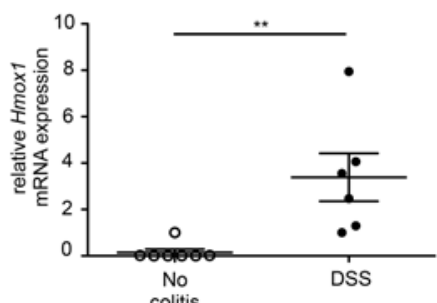

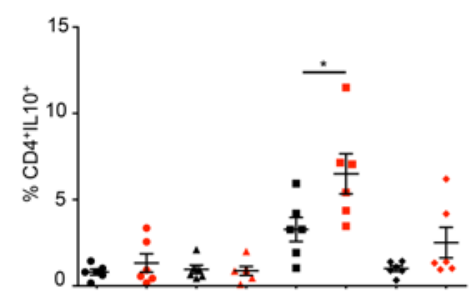

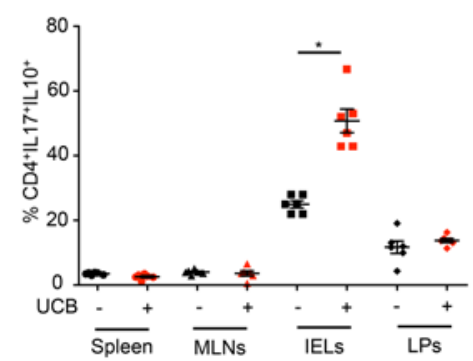

Figure 1. UCB improves recovery after induction of DSS colitis. WT mice $(n=12)$ were treated with $3 \%$ DSS for 8 days. DSS treatment was then replaced with normal water for an additional 4 days. For the whole duration of the experiment, mice were administered either vehicle $(n=6)$ or UCB $(n=6)$ at $20 \mu \mathrm{mol} / \mathrm{kg} /$ day. (A) Mean \pm SEM disease activity index in vehicle and UCB-treated WT mice. (B) Mean \pm SEM colon length (cm) at the time of harvesting. (C) H\&E staining of colon sections (original magnification, $\times 10$ ); arrows indicate the area magnified in the insets $(\times 20)$; mean \pm SEM histology score at the time of harvesting is also shown. (D) Representative flow cytometry plots of CD4 and IL-17 or IL-10 fluorescence of mononuclear cells obtained from the spleen, MLNs, IELs, and LPs of vehicle and UCB-treated WT mice. (E) Mean \pm SEM frequency of CD4+IL-17+', CD4 $4^{+} I L-10^{+}$, and CD4 ${ }^{+}$IL-17+IL-10+ Iymphocytes among spleen, MLN, IEL, and LP mononuclear cells. (F) Mean \pm SEM relative Hmox1 mRNA expression in spleen and MLN-derived mononuclear cells in untreated and DSS-treated mice. Data are representative of 1 of 3 independent experiments. $P$ values derived using paired $t$ test. ${ }^{*} P \leq 0.05 ;{ }^{* *} P \leq 0.01 ;{ }^{* *} P \leq 0.001$. DSS, dextran sodium sulfate; UCB, unconjugated bilirubin; MLNs, mesenteric lymph nodes; IELs, intraepithelial lymphocytes; LPs, lamina propria lymphocytes.

Failure of Th17 cells in Crohn's disease patients to respond to UCB. UCB immunomodulatory properties were also explored in Th17 cells obtained from the peripheral blood of patients with Crohn's disease, in whom the Th17 cell subset represents one of the predominant $\mathrm{T}$ effector populations involved in tissue damage $(15,35$, 36). In healthy subjects, exposure of Th17 cells to UCB increased the frequency of FOXP $3^{+}$cells (Figure $3 \mathrm{~A}$ ), whereas in Crohn's disease no increase in the proportion of these cells was observed (Figure 3A). Comparable results were obtained when considering FOXP3 mRNA levels (Supplemental Figure 1A; supplemental material available online with this article; https://doi.org/10.1172/jci.insight.92791DS1). The effect of UCB on FOXP3 appeared to be restricted to the Th17 subset, as no change in the proportion of FOXP $3^{+}$lymphocytes was noted among the Th1 and Th2 subpopulations (Supplemental Figure 1B), obtained upon conditioning of CD4 ${ }^{+}$cells in the presence of IL-12 plus anti-IL-4 (Th1 cells) or IL-4 plus anti-IFN- $\gamma$ (Th2 cells).

As we had previously shown that expression of the ectonucleotidase CD39 modulates effector Th17 cell properties and confers on them features typical of immunosuppressive cells $(18,37)$, we tested the impact of UCB exposure on Th17 CD39 expression in healthy subjects and patients with Crohn's disease. 
A

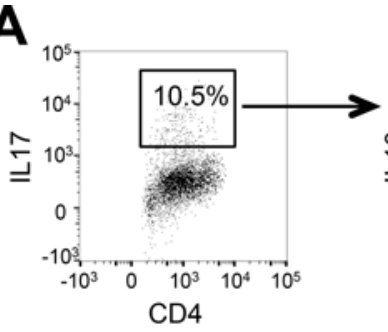

B

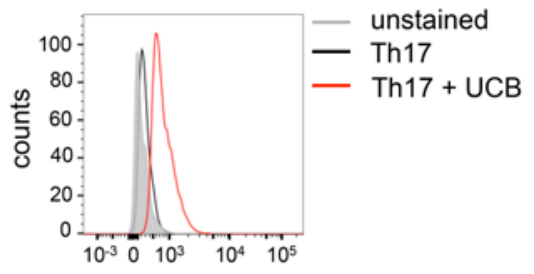

D IL10
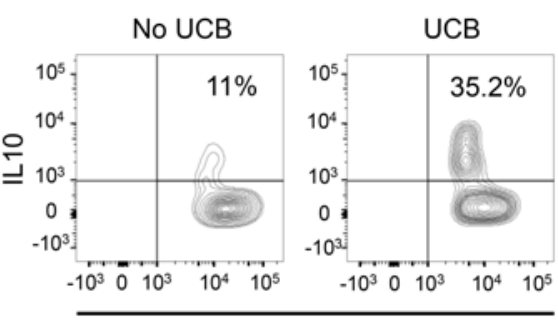

CD4

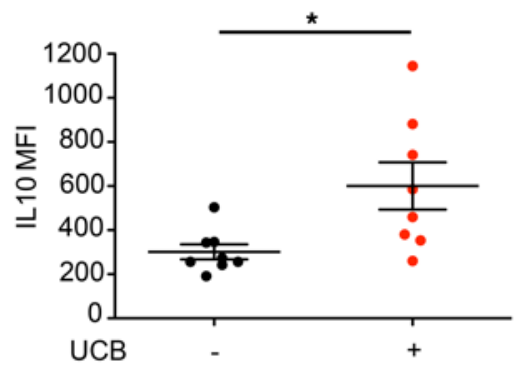

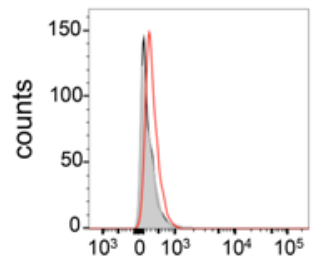

IL17

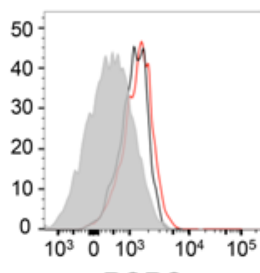

RORC

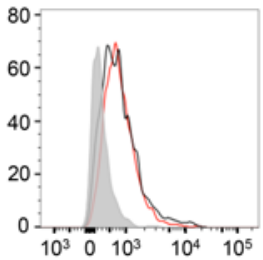

IL23R

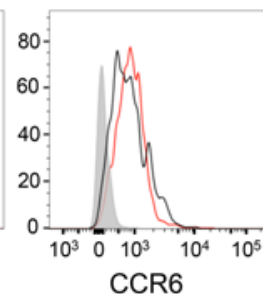

CCR6
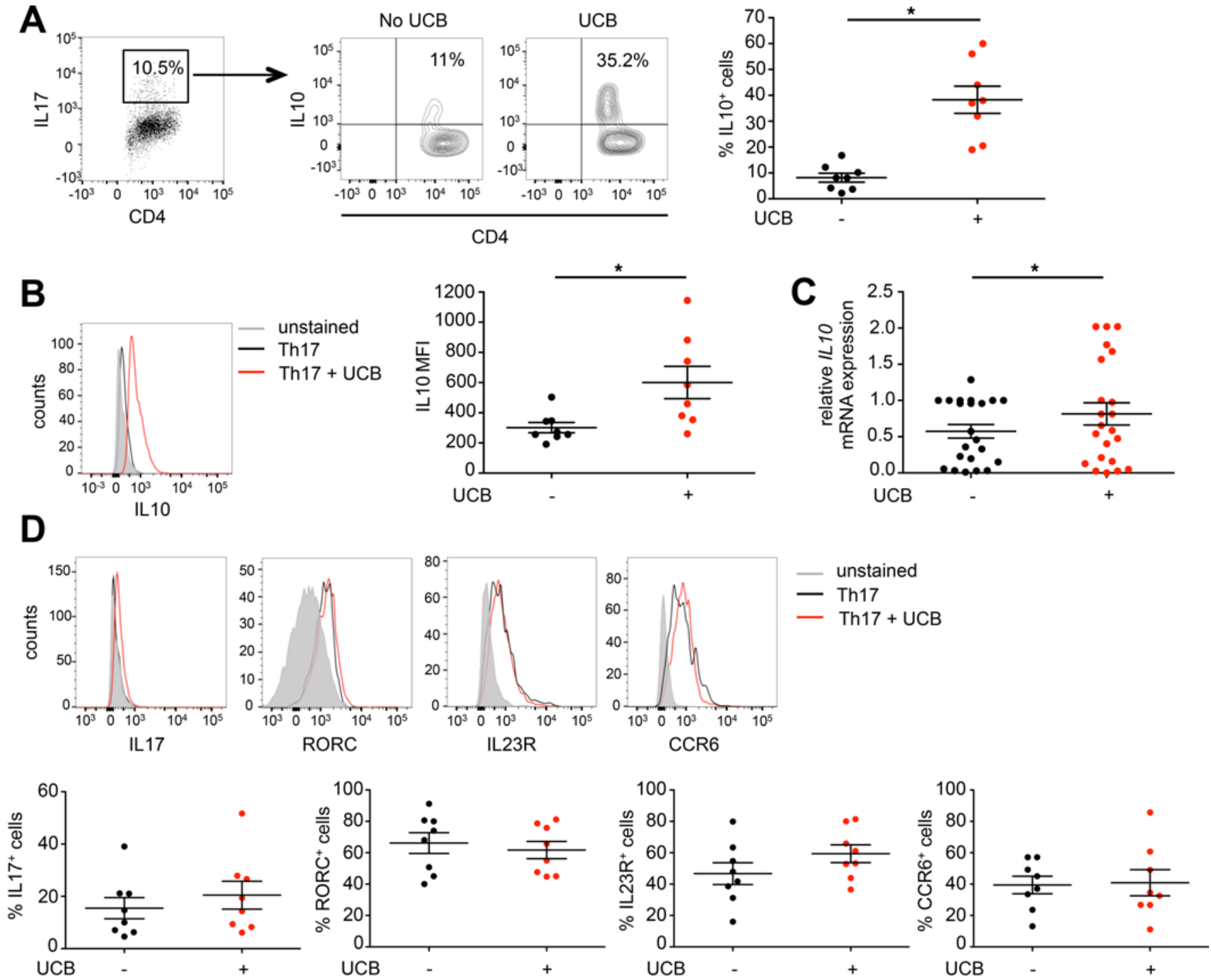

E

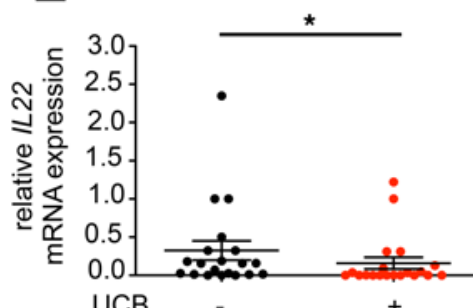

$\mathbf{F}$

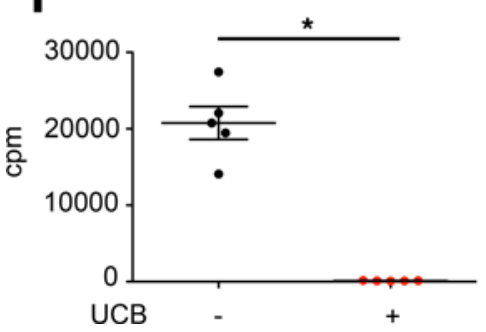

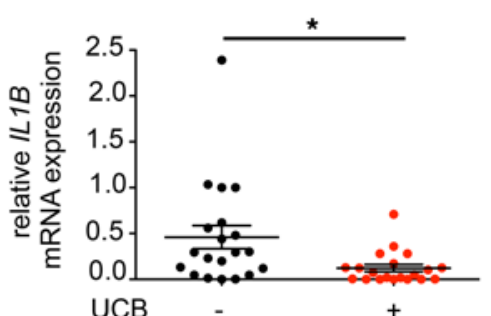

G

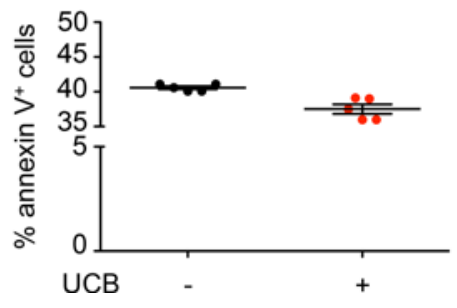

Figure 2. UCB boosts IL-10 expression in human Th17 cells. (A) CD4 cells were polarized in the presence of Th17-skewing conditions; on day 6 , cells were exposed to UCB. Cells were initially gated on $\mathrm{CD} 4^{+} \mathrm{IL}-17^{+}$lymphocytes, and then the frequency of IL-10+ cells within the $\mathrm{CD} 4^{+} \mathrm{IL}-17^{+}$subset was measured. Representative dot plot of CD4 and IL-17 fluorescence and contour plots of CD4 and IL-10 fluorescence in the absence and presence of UCB are shown. Mean \pm SEM frequency of IL-10-producing cells in untreated and UCB-treated Th17 cells ( $n=8$ healthy subjects [HS]). (B) Histogram of IL-10 MFI of untreated and UCB-treated Th17 cells from a representative healthy control. Cumulative data from $n=8 \mathrm{HS}$ are also shown. (C) Mean \pm SEM relative IL10 mRNA expression in untreated and UCB-treated Th17 cells ( $n=22 \mathrm{HS}$ ). (D) Histograms of IL-17, RORC, IL-23R, and CCR6 MFI from a representative healthy control. Mean \pm SEM frequency of IL-17+, RORC+, $\mathrm{IL}^{2} 23 \mathrm{R}^{+}$, and $\mathrm{CCR6}^{+}$lymphocytes within untreated and UCBtreated Th17 cells from $n=8 \mathrm{HS}$ is also shown. (E) Mean \pm SEM relative IL22 and ILIB mRNA expression in untreated and UCBtreated Th17 cells ( $n=12 \mathrm{HS}$ ). (F) Mean \pm SEM cpm of untreated and UCB-treated Th17 cells $(n=5 \mathrm{HS})$. (G) Mean \pm SEM frequency of annexin $\mathrm{V}^{+}$cells within untreated and UCB-treated Th17 cells ( $n=5 \mathrm{HS}$ ). $P$ values derived using paired $t$ test. ${ }^{*} P \leq 0.05$. UCB, unconjugated bilirubin; MFI, mean fluorescence intensity; RORC, RAR-related orphan receptor C; IL-23R, IL-23 receptor. 
UCB boosted the frequency of CD39+ cells among the Th17 subset in healthy individuals and Crohn's disease subjects, though the levels observed in patients did not equalize those observed in controls (Figure 3B). Similar results were obtained when analyzing ENTPD1 mRNA levels (Supplemental Figure 1C).

Exposure to UCB increased to some extent the proportion of $\mathrm{CD} 39^{+}$cells among the Th1 subset but did not have any effect on Th2 lymphocytes (Supplemental Figure 1D).

When evaluating CD73, the ectoenzyme that works in tandem with CD39 and hydrolyzes AMP into adenosine, we noted increases in the proportion of $\mathrm{CD}^{2} 3^{+}$lymphocytes among Th17 cells derived from both healthy subjects and patients with Crohn's disease (Figure 3C).

In Crohn's disease, exposure to UCB of Th17 cells obtained from lamina propria-derived CD4 ${ }^{+}$cells in the presence of Th17-polarizing conditions, did not result in CD39, CD73, and FOXP3 upregulation (Figure 3D), indicating that Th17 cells from patients are resistant to the immunomodulatory effects of UCB in the site of damage. Further analysis was performed on Th17 cells obtained from biopsied inflamed and noninflamed (used as intraindividual control) colon areas of the same patient. No difference was noted in the frequency of $\mathrm{FOXP}^{+}, \mathrm{CD}^{+}{ }^{+}$, and $\mathrm{CD} 3^{+}$cells upon exposure to UCB (Figure 3, E-G). The proportion of $\mathrm{FOXP}^{+}, \mathrm{CD}^{3} 9^{+}$, and $\mathrm{CD}^{2} 3^{+}$lymphocytes among Th17 cells obtained from either peripheral blood or lamina propria did not differ between untreated patients and those patients receiving steroids and/or immunomodulatory drugs (i.e., 6-mercaptopurine). Levels of HMOX1 mRNA in peripheral blood-derived Th17 cells tended to be lower in Crohn's disease patients than in healthy controls, possibly as a result of long-standing disease in the group of patients tested (Supplemental Figure 1E).

In a manner distinct from that observed in healthy controls (Figure 2F), UCB had decreased inhibitory effects on the proliferation of peripheral blood-derived Th17 cells, which were obtained from patients with Crohn's disease (Supplemental Figure 1F).

Analysis of cell suppressive function was determined as the ability of Th17 cells, sorted as CXCR3 $\mathrm{CCR}^{+}$lymphocytes following $\mathrm{CD}^{+}$cell exposure to Th17-polarizing conditions (Figure $3 \mathrm{H}$ ), to control IFN- $\gamma$ and IL-17 production by $\mathrm{CD} 4^{+} \mathrm{CD} 25^{-}$responders. We noted that exposure to UCB boosted the immunoregulatory properties of Th17 cells in healthy controls (Figure 3I). In contrast, UCB did not have significant effects on the suppressor capacity of Th17 cells from patients (Figure 3I).

No effect on the inhibition of IFN- $\gamma$ and IL-17 production by responder cells was noted following Th1 or Th2 cell exposure to UCB (Supplemental Figure 1G), indicating that UCB immunoregulatory properties were predominantly impacting Th17 cell function.

Evaluation of ectoenzymatic activity showed that UCB increased phosphohydrolysis of extracellular nucleotides in the culture supernatant of Th17 cells from healthy subjects but did not have any effect on Th17 cells obtained from patients (Figure 3J). TLC analysis showed that in both healthy subjects and patients UCB reduced Th17 cell adenosine deaminase (ADA) activity, as demonstrated by lower conversion of adenosine into inosine (Supplemental Figure 2A). UCB exposure, however, appeared to impact Th17 cell ADA activity (Supplemental Figure 2A), rather than expression (Supplemental Figure 2B).

Collectively, these data show that Th17 cells isolated from patients with Crohn's disease are refractory to UCB immunoregulatory properties. Further, UCB preferentially impacts Th17 cell ATPase activity, this property being impaired in Th17 cells from patients with Crohn's.

$U C B$ immunomodulatory effects are linked to CD39 and AHR expression. To explore whether the immunosuppressive properties of UCB depend on the expression of CD39, UCB was injected into Entpd1 ${ }^{-/-}$mice, which were concomitantly treated with DSS for the first 8 days and then with normal water for the follow-

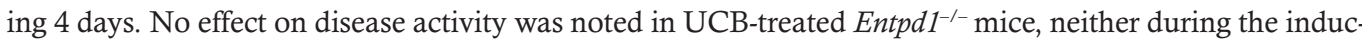
tion nor recovery phase (Figure 4A). Further, no changes in colon length (Figure 4B), histopathological features (Figure 4C), and frequencies of CD4 $4^{+} \mathrm{IL}-17^{+}$(Figure $4 \mathrm{D}$ and Supplemental Figure $3 \mathrm{~A}$ ), CD $4^{+} \mathrm{IL}-10^{+}$ (Figure 4D and Supplemental Figure 3B), and CD4+IL-17 ${ }^{+} \mathrm{IL}-10^{+}$cells (Figure 4D) were observed between UCB-treated and untreated mice. That UCB immunoregulatory effects might be mediated by CD39 was also supported by the finding of an increased proportion of $\mathrm{CD}^{+} \mathrm{CD} 39^{+}$cells among IELs and lamina propria lymphocytes (LPs) obtained from UCB-treated versus untreated WT mice (Figure 4E). Analysis at the mRNA level showed decreased Entpd1 expression in the spleen but increased expression in the IEL fraction (Figure 4F).

AHR modulates Treg and Th17 cell immunity $(21,22,38,39)$. AHR expression has been linked to nonpathogenic Th17 cells (40) and its activation has been found to induce Treg responses through upregulation of CD39, the expression of which results in ATP scavenging (24). Indeed, AHR directly transactivates the 
A
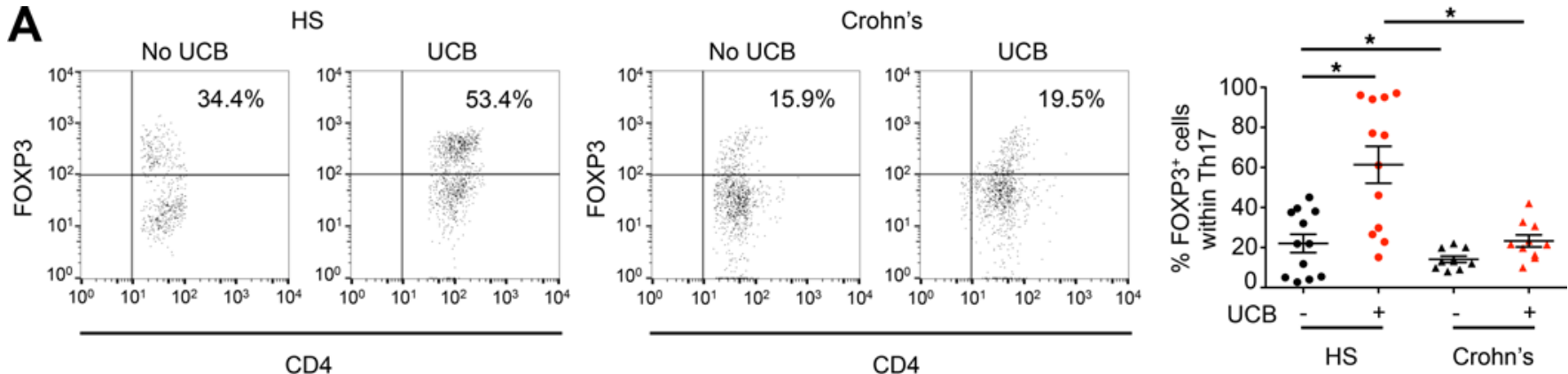

B

CD4

CD4
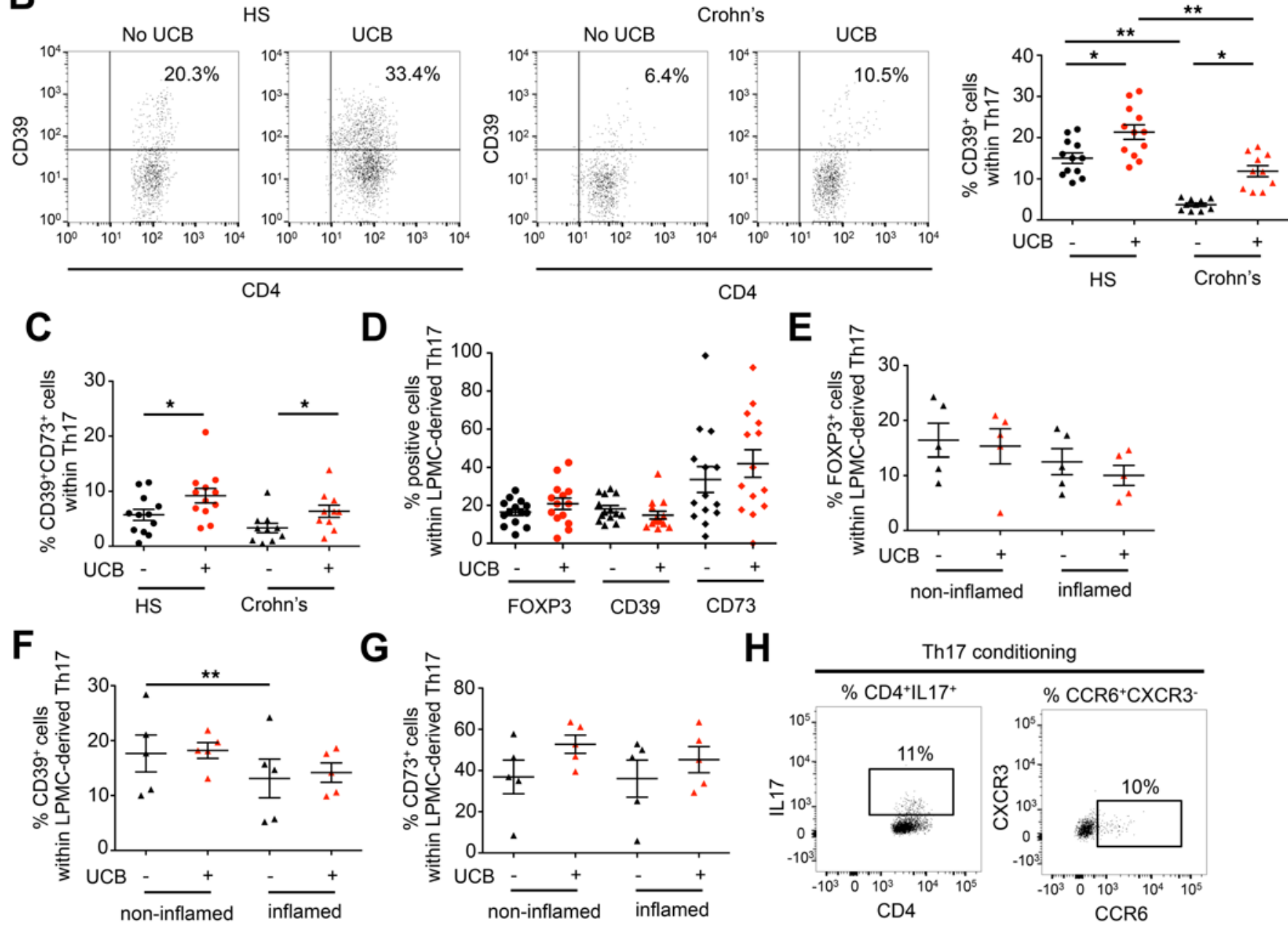

G

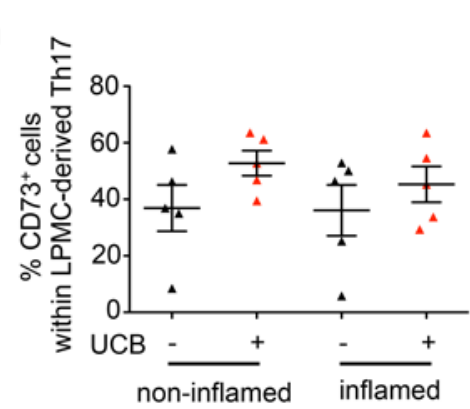

H

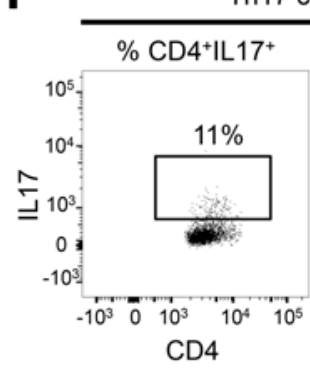

Th17 conditioning
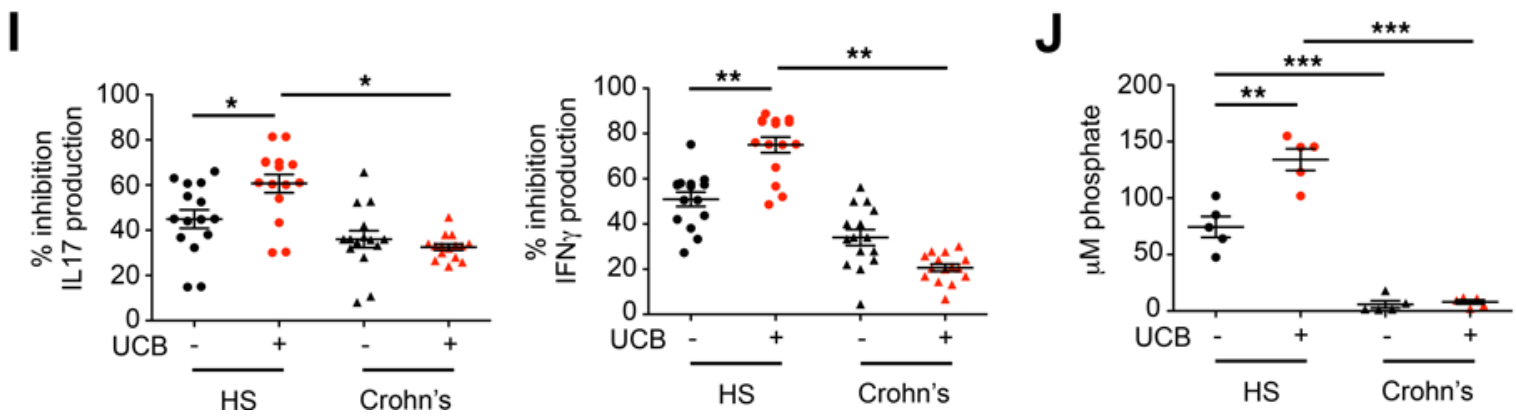

Figure 3. UCB confers Th17 regulatory properties in healthy subjects but not in Crohn's disease patients. Frequencies of FOXP3 ${ }^{+}, \mathrm{CD} 9^{+}$, and $\mathrm{CD73}{ }^{+}$ cells were determined after polarizing CD4 $4^{+}$cells under Th17 conditions and UCB treatment. Cells were initially gated on CD4+IL-17+ and the frequency of $\mathrm{FOXP3}^{+}, \mathrm{CD}^{+} 9^{+}$, and FOXP3 $3^{+}$lymphocytes determined. CD4 and FOXP3 (A) or CD39 (B) fluorescence of Th17 cells. Mean \pm SEM frequency of FOXP3 ${ }^{+}$and CD39+ Iymphocytes within Th17 cells is also shown ( $n=12 \mathrm{HS}$ and $n=10$ Crohn's). (C) Mean \pm SEM frequency of CD73 ${ }^{+}$cells within CD39+ Th17 ( $n=12$ HS 
and $n=10$ Crohn's). (D) Mean \pm SEM frequency of FOXP3+, CD39+, and CD73+ lymphocytes within LPMC-derived Th17 cells ( $n=14$ Crohn's). (E-G) Mean \pm SEM frequency of FOXP3 ${ }^{+}, \mathrm{CD}^{+}{ }^{+}$, and $\mathrm{CD73}^{+}$lymphocytes within LPMC-derived Th17 cells from noninflamed and inflamed colon areas ( $n=5 \mathrm{Crohn's).} \mathrm{(H)}$ Suppressive function of untreated and UCB-treated Th17 was assessed following sorting of CCR6+CXCR3- cells from CD4+ lymphocytes polarized under Th17 conditions. CD4, IL-17, CCR6, and CXCR3 fluorescence from 1 HS is shown. (I) Mean \pm SEM percentage inhibition of IL-17 and IFN- $\gamma$ production by CD4 ${ }^{+C D 25}$ responders in the presence of untreated or UCB-treated Th17 cells ( $n=15$ HS and $n=15$ Crohn's). (J) Mean \pm SEM free phosphate concentrations in the supernatant of Th17 cells ( $n=5 \mathrm{HS}$ and $n=5$ Crohn's). $P$ values derived using 1-way ANOVA followed by Tukey's multiple comparisons test. ${ }^{*} P \leq 0.05 ;{ }^{* *} P \leq 0.01 ;{ }^{* *} P \leq 0.001$. HS, healthy subjects; UCB, unconjugated bilirubin; LPMCs, lamina propria-derived mononuclear cells.

Entpd1 promoter (41). As UCB serves as an endogenous ligand for AHR (42, 43), we tested whether the course of DSS-induced colitis might be impacted by UCB administration in $A h r^{d}$ mice. As shown in Figure 5, A and B, no effects on disease activity and colon length were noted in UCB-treated and untreated $A h r^{d}$ mice. Abundant leukocytic infiltration and large edematous areas were observed between smooth muscle layers also after UCB administration (Figure 5C). No differences in the frequencies of CD4 $4^{+} \mathrm{IL}-17^{+}$(Figure 5D and Supplemental Figure 4A), CD4 ${ }^{+} \mathrm{IL}-10^{+}$(Figure 5D and Supplemental Figure 4B), and CD4 $4^{+} \mathrm{IL}-$ $17^{+} \mathrm{IL}-10^{+}$(Figure 5D) cells were noted between untreated and treated animals. No increase in the frequency of $\mathrm{CD}^{+} \mathrm{CD} 39^{+}$lymphocytes was noted following UCB treatment in any of the cell compartments studied (Figure 5E and Supplemental Figure 4C). That UCB effects were mediated through AHR was also supported by the evidence of an increased expression of the AHR responsive gene Cypla1 in lymphocytes obtained from UCB-treated versus untreated WT mice (Figure 5F). No increase in Cyp 1al expression was noted in UCB-treated $A h r^{d}$ mice (Figure 5F). Collectively, these data indicate that UCB immunomodulatory effects are mediated by AHR-dependent CD39 upregulation.

Decreases in CD39 expression by Th17 cells in Crohn's disease are linked to impaired AHR expression. We next tested whether low CD39 expression in Th17 cells from Crohn's disease patients was associated with alterations in AHR expression. As depicted in Figure 6A, AHR mRNA levels and the frequency of $\mathrm{AHR}^{+}$cells were lower in peripheral blood-derived Th17 cells from Crohn's patients as compared with controls. In lamina propria-derived Th17 cells, the proportion of $\mathrm{AHR}^{+}$cells was lower in patients with active disease than in those at remission and, within the same patient, in inflamed compared with noninflamed colon areas (Figure 6B and Supplemental Figure 5A).

To determine whether the increase in CD39 expression upon exposure of Th17 cells to UCB resulted from AHR engagement, Th17 cells from healthy subjects were treated with the AHR inhibitor (AHRi) CH223191 (39). As depicted in Figure 6C, AHRi-treated Th17 cells showed decreased CD39 upregulation when exposed to UCB. Further, following AHRi treatment, UCB-treated Th17 cells show decreased suppressive activity (Supplemental Figure 5B).

\section{Discussion}

Our results show that UCB immunomodulatory properties are mediated through AHR-dependent CD39 upregulation. We also show that decreased AHR levels and/or dysfunction can compromise Th17 cell suppressive responses. This mechanism is associated with the failure of CD39 upregulation, because of defective UCB-AHR interactions and crosstalk. These pathways, when aberrant as in IBD, have the end result of decreasing CD39 expression and thereby might interfere with the regulation of pathogenic Th17 cells.

Beneficial properties of low levels of exogenous UCB are noted both in vivo and in vitro. Experimental and histopathological amelioration of colitis was observed during disease recovery alongside lower frequencies of $\mathrm{CD} 4^{+} \mathrm{IL}-17^{+} \mathrm{T}$ cells in the spleen, MLNs, and lamina propria, and higher proportions of $\mathrm{CD} 4^{+} \mathrm{IL}-10^{+}$lymphocytes infiltrating the colon epithelia. Although our data suggest that these changes are the consequence of the effector T cell and Treg subpopulations' exposure to UCB, these effects may synergize with the modulation of antigen-presenting cell function by UCB, as previously described $(2,3)$.

As one of the predominant effects of UCB on the lamina propria T cell compartment was the decrease in the proportion of IL-17-producing $\mathrm{CD} 4^{+} \mathrm{T}$ cells, we focused on investigating the in vitro immunomodulatory properties of UCB on human Th17 cells. Despite maintaining phenotypic features of effectors, Th17 cells exposed to UCB upregulated the expression of regulatory molecules and became strongly effective at suppressing responder cell effector function. Lack of responsiveness to UCB, however, as noted in Crohn's disease, resulted in no acquisition of a regulatory phenotype. Our results suggest that interference with Th17 cell machinery may compromise the ability of these cells to become regulated by UCB and transition to a suppressive state. 
A

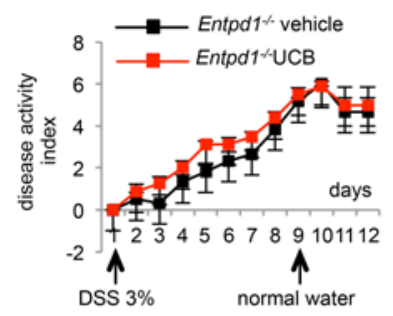

B

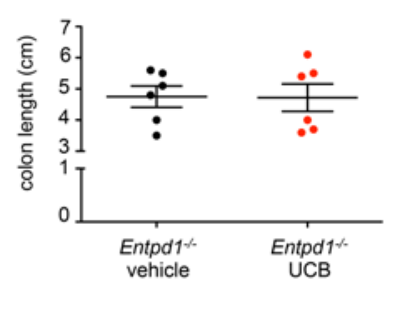

C

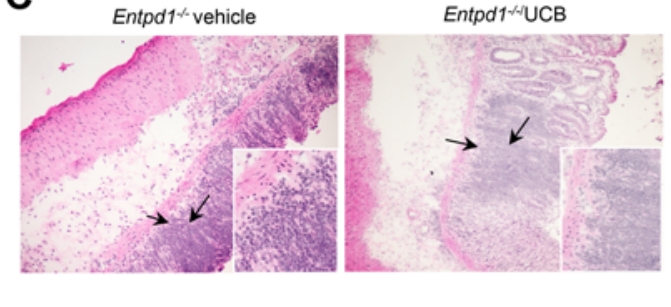

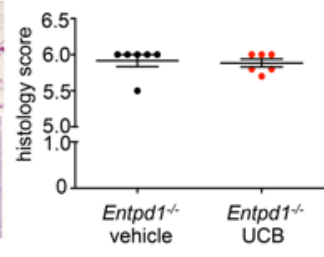

D
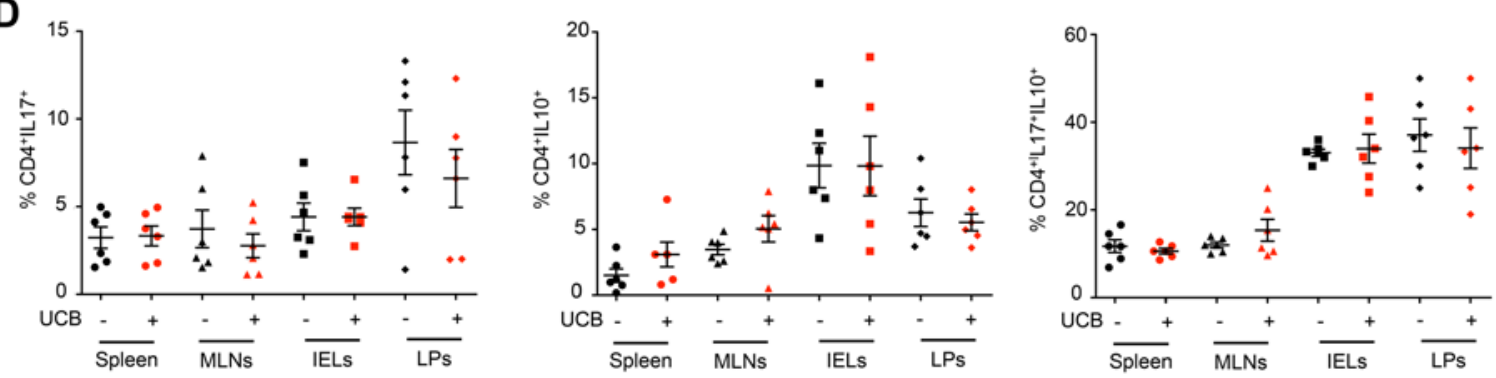

E
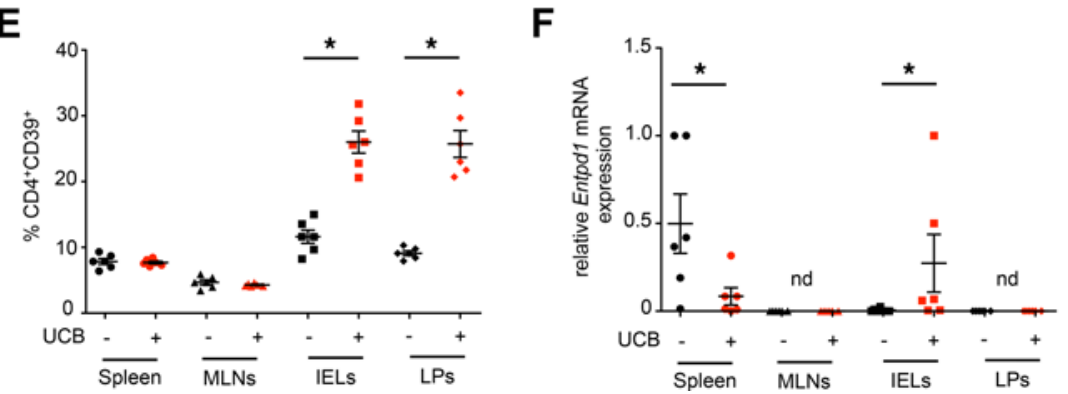

Figure 4. Failure of UCB immunoregulatory properties in Entpd1 1/- mice. Entpd1 $1^{-1-}$ mice $(n=12)$ were given $3 \%$ DSS for 8 days and then normal water for additional 4 days. For the whole duration of the experiment, mice were administered either vehicle $(n=6)$ or UCB $(n=6)$ at $20 \mu \mathrm{mol} / \mathrm{kg} / \mathrm{day}$. (A) Mean \pm SEM disease activity index in vehicle- and UCB-treated Entpd1 1- mice. (B) Mean \pm SEM colon length (cm) at the time of harvesting. (C) H\&E staining of colon sections (original magnification, $\times 10$ ); arrows indicate the area magnified in the insets $(\times 20)$; mean \pm SEM histology score at the

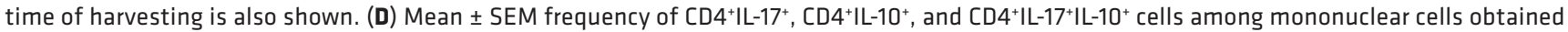
from spleen, MLNs, and from IELs and LPs of Entpd1 1/- mice. (E) Mean \pm SEM frequency of CD4+CD39+ lymphocytes in WT mice. (F) Mean \pm SEM relative Entpd1 mRNA expression in the total lymphocyte fraction obtained from spleen and IELs. Data are representative of 1 of 3 independent experiments. $P$ values derived using paired $t$ test. ${ }^{*} P \leq 0.05$. nd: not done. DSS, dextran sodium sulfate; UCB, unconjugated bilirubin; MLNs, mesenteric lymph nodes; IELs, intraepithelial lymphocytes; LPs, lamina propria lymphocytes.

The potential mechanism involved in UCB immunoregulatory properties resides in the upregulation of CD39 by Th17 cells. Modulation of Th17 cells involves P2 signaling and inhibition of P2X7 activation decreases IL-6 levels and STAT-3 effects, both impacting Th17 cell differentiation (44). These mechanisms may act in concert with induction of CD39, which shifts the balance towards P1 adenosinemediated signaling and modulates Th17 cell pathogenic potential (18).

The importance of CD39 in the modulation of experimental colitis by UCB was corroborated by in vivo data and strengthened by the observation that treatment of WT mice with UCB increased the proportion of $\mathrm{CD} 4^{+} \mathrm{CD} 39^{+}$cells in the colon.

To define the pathway resulting in CD39 upregulation, we analyzed the expression of AHR in circulating and lamina propria-derived Th17 cells. Previous data have demonstrated that engagement of AHR induces Tregs that suppress via CD39 $(24,38,41)$. Our data show that UCB, which serves as an endogenous AHR ligand $(42,43)$ (Figure 5F), acts as a Th17 cell modulator via CD39. Notably, AHR expression is low in IBD-derived Th17 cells, possibly explaining the reason for the inability of these cells to respond to UCB and, subsequently, undergo regulation. Further demonstration of AHR involvement in this proposed immunomodulatory pathway of Th17 cells was shown by lack of clinical and histopathological amelioration of colitis in $A h r^{d}$ mice dosed with UCB at the end of the observation period. 
A

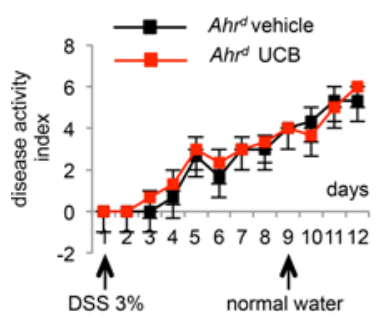

D

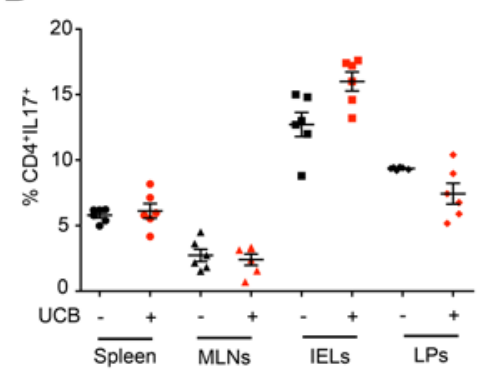

$\mathbf{E}$

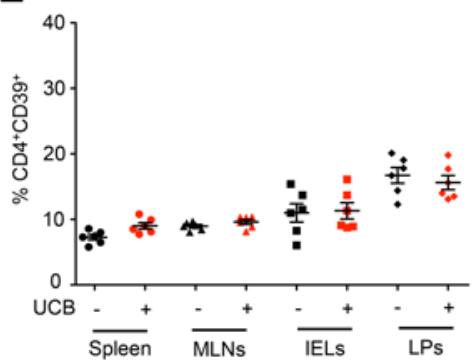

B

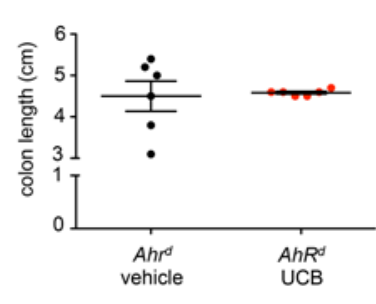

C
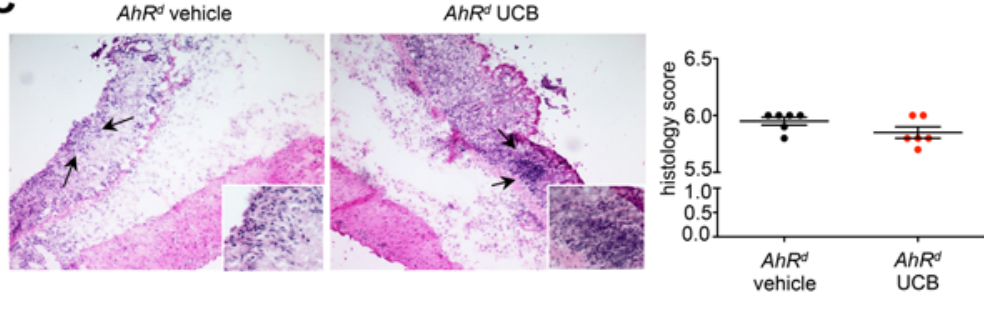

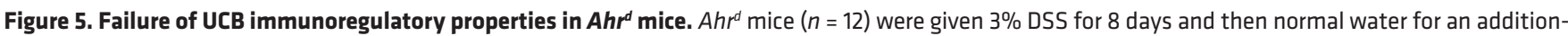
al 4 days. For the whole duration of the experiment mice were administered either vehicle $(n=6)$ or UCB ( $n=6)$ at $20 \mu \mathrm{mol} / \mathrm{kg} / \mathrm{day}$. (A) Mean \pm SEM disease activity index in vehicle- and UCB-treated $A h r^{d}$ mice. (B) Mean \pm SEM colon length (cm) at the time of harvesting. (C) H\&E staining of colon sections (original magnification, $\times 10)$; arrows indicate the area magnified in the insets $(\times 20)$; mean \pm SEM histology score at the time of harvesting is also shown. Mean \pm SEM frequency of CD4+ IL-17+, CD4+IL-10+, CD4+IL-17+IL-10+ (D), and CD4+CD39+ (E) lymphocytes among mononuclear cells obtained from spleen, MLNs, and from IELs and LPs. (F) Mean \pm SEM relative Cyp1a1 mRNA expression in lymphocytes obtained from MLNs of untreated and UCB-treated WT and Ahr ${ }^{d}$ mice. Data are representative of 1 of 3 independent experiments. $P$ values derived using paired $t$ test. ${ }^{*} P \leq 0.01$. Ahr, aryl hydrocarbon receptor; DSS, dextran sodium sulfate; UCB, unconjugated bilirubin; MLNs, mesenteric Iymph nodes; IELs, intraepithelial lymphocytes; LPs, lamina propria Iymphocytes.

Of note, these mice did not upregulate CD39 in any of the immune cell compartments, when subjected to DSS treatment (Figure 5E).

There is evidence that Th17 cells acquire immunoregulatory features that are associated with attenuation of the pathogenic potential $(18,45)$. Our findings indicate that UCB enhances control of Th17 cell regulatory properties, as clearly highlighted by our in vitro data, and boosts immunoregulation in vivo by decreasing IL-17 production and by increasing CD39 and IL-10 expression levels by CD4 ${ }^{+}$cells in the colonic compartment. These in vitro and in vivo studies support a role for UCB in modulating pathogenicity while boosting immunoregulation.

It remains unclear whether the beneficial effects of UCB on the Th17 cell immune responsiveness depend solely on immunosuppressant properties effected by AHR or whether these can also be linked to UCB antioxidant effects, as previously shown for macrophages (46). Further studies will explore this possibility and further dissect out whether UCB antioxidant effects might also impact the interaction with AHR as well as derived immunoregulatory effects.

Our observations in patients with Crohn's disease show that the pathological Th17 cells fail to undergo regulation in response to $\mathrm{UCB}$, and do not increase $\mathrm{CD} 39$ expression. This might indicate persistent immune deviation in the proinflammatory state and could be an acquired phenotype designating resistance to UCB/ AHR signaling. Pharmacological administration of other AHR ligands or inhibition of hypoxia-inducible 
A

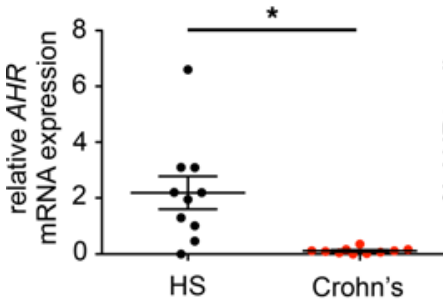

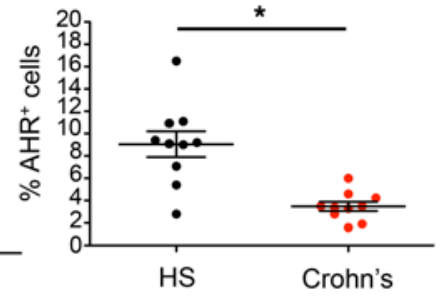

B

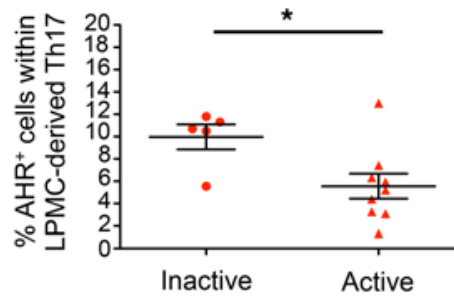

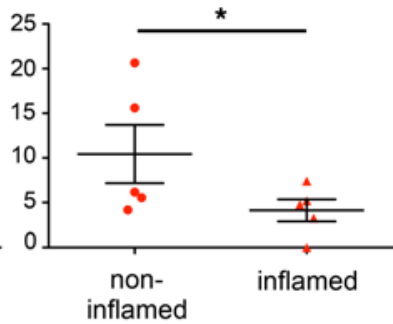

C
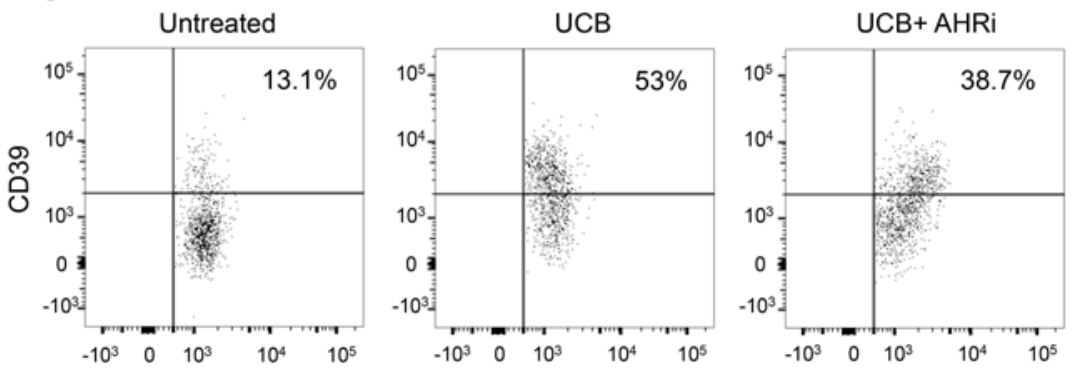

CD4

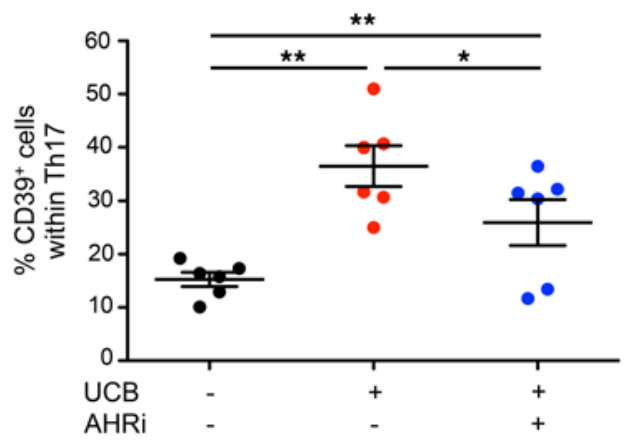

Figure 6. Impaired AHR expression in Th17 cells from Crohn's patients. (A) Relative AHR mRNA expression and frequency of AHR+ lymphocytes within Th17 cells from $n=10 \mathrm{HS}$ and $n=10$ Crohn's patients. Results are expressed as mean \pm SEM. (B) Mean \pm SEM frequency of AHR+ lymphocytes within LPMC-derived Th17 cells in inactive $(n=5)$ and active $(n=9)$ Crohn's and in noninflamed versus inflamed colon areas ( $n=5$ Crohn's). (C) Flow cytometry plots of CD4 and CD39 fluorescence of untreated, UCB-treated, and UCB + AHRi-treated Th17 cells from a representative HS. Cumulative data (mean \pm SEM) from $n=6 \mathrm{HS}$ are also shown. $P$ values derived using paired (A) or unpaired (B) $t$ test, or 1-way ANOVA followed by Tukey's multiple comparisons test (C). ${ }^{*} P \leq 0.05$; ${ }^{* *} P \leq 0.01$. AHR, aryl hydrocarbon receptor; HS, healthy subjects; LPMC, lamina propria mononuclear cell; UCB, unconjugated bilirubin; AHRi, aryl hydrocarbon receptor inhibitor.

factor $1 \alpha$ to boost AHR signaling (41), could promote salutary effects of UCB, providing another strategy in IBD. Alternatively, administration of exogenous apyrases/ectonucleotidases or other modes to upregulate CD39, e.g., via IL-27, might be considered. These adjunct approaches would likewise facilitate the suppression of Th17 effector potential by enhancing UCB functionality in a nontoxic and well-tolerated manner and dampen inflammation in this important chronic inflammatory disease state.

\section{Methods}

Mice

The derivation and characterization of C57BL/6 Entpd1 ${ }^{-/-}$and Ahr $r^{d}$ mice on the C57BL6 background has been previously described $(21,28,47)$. C57BL/ 6 WT mice were purchased from Taconic and cohoused for 4 weeks with Entpd1 $1^{-/}$and $A h r^{d}$ mice before being subjected to DSS colitis. Ten- to 12-week-old males were studied in accordance with standard institutional animal welfare guidelines.

\section{Subjects}

PBMCs and lamina propria mononuclear cells (LPMCs) were isolated from 71 patients with Crohn's disease (median Harvey-Bradshaw Index, 4, range 0 to 10), recruited from the Gastroenterology Division, Beth Israel Deaconess Medical Center. Of these patients, 32 were studied during active disease while 39 were in clinical remission. At the time of study, 37 patients were receiving infliximab, 7 were on steroids, and 11 were receiving 6-mercaptopurine. PBMCs were also isolated from 45 healthy subjects (Blood Donor Center at Children's Hospital, Boston, Massachusetts, USA).

\section{Cell isolation}

Mouse. Mononuclear cells were obtained from the spleen, MLNs, and from colon IEL and LP fractions. IELs and LPs were isolated following incubation in dissociation buffer $\left(\mathrm{HBSS} \mathrm{Ca}^{2+}\right.$ - and $\mathrm{Mg}^{2+}$-free containing $2 \%$ 
FBS, $5 \mathrm{mM}$ EDTA, $10 \mathrm{mM}$ HEPES) and digestion buffer (HBSS with $\mathrm{Ca}^{2+}$ and $\mathrm{Mg}^{2+}, 10 \% \mathrm{FBS}, 0.5 \mathrm{mg}$ / $\mathrm{ml}$ DNase I [Sigma-Aldrich] and $0.5 \mathrm{mg} / \mathrm{ml}$ collagenase type IV [Worthington Biochemical Corporation]), resuspension in 40\% Percoll, and layering on $80 \%$ Percoll Plus (GE Healthcare Life Sciences).

Human. PBMCs were obtained by density gradient centrifugation on Ficoll-Paque (GE Healthcare) as previously described (18). LPMCs were isolated from freshly biopsied colonic tissue in 23 patients with Crohn's disease ( 15 with active disease and 8 in remission). In 10 patients, colonic tissue was biopsied in both inflamed and noninflamed areas ( 3 to 4 samples per bioptic area) and results obtained from the 2 sites were compared. LPMCs were isolated as previously reported (18).

PBMC and LPMC viability was checked by trypan blue exclusion and always exceeded $98 \%$.

Induction and clinical assessment of experimental colitis C57BL/6 WT $(n=12)$, Entpd1 ${ }^{-/-}(n=12)$, and $A h r^{d}(n=12)$ mice were treated with $3 \%$ DSS in standard drinking water that was provided ad libitum for 8 consecutive days. Mice were also injected i.p. with UCB (Frontiers Scientific) at $20 \mu \mathrm{mol} / \mathrm{kg} /$ day. UCB was resuspended in an aqueous solution containing $2 \mathrm{M}$ $\mathrm{NaOH}$ and $200 \mathrm{mM}$ Tris- $\mathrm{HCl}$ ( $\mathrm{pH}$ 8.4). UCB administration was continued the same dose and frequency after DSS treatment was replaced with normal water for 4 days. Disease activity index (range: $0-7$ ) was calculated on the basis of body weight loss (0: $0 \%-1 \%$; ' 1 ': > 1\%-5\%; ' 2 ': > 5\%-10\%; ' 3 ': > 10\%-15\%; ' 4 ': $>15 \%-20 \%$ ), presence of gross blood ('0': absence of blood; ' 1 ': presence of blood) and stool consistency ('0': firm; ' 1 ' loose; '2': diarrhea) and assessed on a daily basis. On day 12 , mice were sacrificed, colons dissected, and length measured from the ileocecal junction to the anal verge.

\section{Histological evaluation of colitis}

Colonic tissue was removed and assessed for histological evaluation upon freezing in OCT compound. Tissue sections $(6 \mu \mathrm{m})$ were stained with hematoxylin and eosin and examined for evidence of colitis, as previously described (48). Histology score (range: 0-6) was calculated based on the presence of lymphomononuclear cell infiltrate (' 0 ': absence of inflammatory foci; ' 1 ': presence of scattered inflammatory foci; ' 2 ': presence of multiple inflammatory foci; ' 3 ': evidence of transmural lymphomononuclear cell infiltration); crypt elongation/distortion or absence (' 0 ': normal crypt architecture; ' 1 ': presence of elongated crypts; ' 2 ': absence of crypts); and edema formation of the colon wall (' 0 ': absence of edema; ' 1 ': presence of edema) were the parameters considered for histological evaluation, as previously reported $(48,49)$.

\section{In vitro cell conditioning}

Human PBMC- and LPMC-derived CD4 $4^{\mathrm{mem}}$ cells were purified as $\mathrm{CD} 4{ }^{+} \mathrm{CD} 45 \mathrm{RO}^{+} \mathrm{CD} 45 \mathrm{RA}^{-}$lymphocytes (Miltenyi Biotec). CD $4^{\mathrm{mem}}$ were chosen as a starting $\mathrm{CD} 4^{+}$cell population, as we previously demonstrated that $\mathrm{CD} 4^{\mathrm{mem}}$-derived Tregs retain immunosuppressive properties, also in the presence of proinflammatory stimuli (18). The purity of the sorted CD $4^{\mathrm{mem}}$ subset exceeded $92 \%$. CD $4^{\mathrm{mem}}$ were cultured in complete RPMI 1640 medium, supplemented with $2 \mathrm{mM}$ L-glutamine, $100 \mathrm{IU} / \mathrm{ml}$ penicillin, $100 \mathrm{mg} / \mathrm{ml}$ streptomycin, $1 \%$ nonessential amino acids, and 10\% FBS and exposed for 5 days to Th17-skewing conditions, i.e., IL-6 (50 $\mathrm{ng} / \mathrm{ml}), \mathrm{IL}-1 \beta$ (10 ng/ml), TGF- $\beta$ (3 ng/ml) (18), and with Dynabeads Human T Activator CD3/CD28 for $\mathrm{T}$ cell expansion (bead/cell ratio, 1:50) (Thermo Fisher Scientific). In parallel experiments, CD4 ${ }^{\mathrm{mem}}$ were exposed to Th1-skewing conditions, i.e., IL-12 (catalog 219-IL) (20 ng/ml) + anti-IL-4 (catalog MAB204) $(10 \mu \mathrm{g} / \mathrm{ml})$, or Th2, i.e., IL-4 (catalog 204-IL) $(10 \mathrm{ng} / \mathrm{ml})+\operatorname{anti-IFN}-\gamma$ (catalog MAB285) $(10 \mu \mathrm{g} / \mathrm{ml})$. All cytokines and neutralizing Abs were from R\&D Systems. On day 6, cells were treated for the last 6 hours of culture with $20 \mu \mathrm{M}$ UCB that was resuspended as indicated above. This concentration of UCB was chosen after performing preliminary experiments in which concentrations ranging from 10 to $60 \mu \mathrm{M}$ were tested. A $20 \mu \mathrm{M}$ concentration was chosen as it was associated with less toxicity to the cells, as shown by trypan blue viability test and frequency of annexin $\mathrm{V}^{+}$lymphocytes. UCB resuspension and addition to the cultures was carried out, while also limiting light exposure to the minimum.

In some experiments, the AHRi CH223191 (Sigma-Aldrich) was added at $3 \mu \mathrm{M}$ (39) to polarized Th17 cell cultures.

\section{Flow cytometry staining}

Flow cytometry was performed following cell incubation with FITC-, PE-, Pe-Cy7-, Pacific Blue (PB)-, APC-, Pe-Cy5-, and PerCP Cy5.5-conjugated anti-human Abs against CD4 (clone OKT4), CD45RO 
(clone UCHL1), CD45RA (clone HI100), CCR6 (clone G034E3), CXCR3 (clone G025H7), CD39 (clone A1), CD73 (clone AD2) (all from Biolegend), and IL-23R (R\&D Systems, clone 218213). The frequency of positive cells and MFI of FOXP3, RORC, and AHR were assessed by intracellular staining, following cell fixation and permeabilization with Cytofix/Cytoperm (BD Biosciences) and incubation with PE-, APC-, and Pe-Cy7-conjugated Abs against human FOXP3 (clone PCH101), RORC (clone AFKJS-9), and AHR (clone FF3399) (all from eBioscience). The frequency of cytokine-producing cells was determined after exposure to Cell Stimulation Cocktail (eBioscience), used at $2 \mu 1 / \mathrm{ml}$, according to the manufacturer's instructions for 5 hours. Staining was carried out using Alexa Fluor 488-, PE-, APC-, and PerCP Cy5.5conjugated anti-human Abs against IL-17A (clone BL168), IL-10 (clone JES3-9D7), IFN- $\gamma$ (clone 4S.B3), and IL-4 (clone MP4-25D2) (all from Biolegend). Isotype controls were from BD Biosciences. Frequency of annexin $\mathrm{V}^{+}$cells was determined using the FITC Annexin V Apoptosis Detection kit (Biolegend).

When murine mononuclear cells were used, staining was carried out using Abs against mouse CD4 (clone GK1.5), IL-17A (clone TC11-18H101), and IL-10 (clone JES5-16E3) (all from Biolegend). Flow cytometric analysis was performed as previously reported (18). Cells were acquired on a BD LSR II (BD Biosciences) and analyzed using FlowJo 2 software (version 10, Tree Star). Positively stained cell populations were gated based on unstained, single-stained, and isotype-stained controls and fluorescence compensation was adjusted, as based on the fluorescence minus one (FMO) method.

\section{Proliferation assay}

Th17 cell proliferation was performed following cell exposure to Dynabeads Human T Activator CD3/ CD28 (bead/cell ratio, 1:2) and IL-2 (30 IU/ml) for 3 days. Cells were then pulsed with $0.25 \mu \mathrm{Ci} /$ well ${ }^{3} \mathrm{H}$-thymidine and harvested 18 hours later using a cell harvester (Tomten). Incorporated ${ }^{3} \mathrm{H}$ was measured by liquid scintillation spectroscopy (50).

\section{Suppression assay}

Th17 cell ability to suppress autologous $\mathrm{CD} 4^{+} \mathrm{CD} 25^{-}$cell effector function was assessed in coculture experiments, in which Th17 cells were added at a ratio of 1:8 to CD4 ${ }^{+} \mathrm{CD} 25^{-}$targets (18). Th17 cells were sorted as $\mathrm{CCR}^{+} \mathrm{CXCR}^{-}$cells following $\mathrm{CD} 4^{\mathrm{mem}}$ conditioning in the presence of Th17-skewing conditions (see above). The percentage of CCR $6^{+} \mathrm{CXCR} 3^{-}$cells following Th17 conditioning was similar to that of IL-17 ${ }^{+}$ cells (Figure $3 \mathrm{H}$ ). Parallel cultures of $\mathrm{CD}^{+} \mathrm{CD} 25^{-}$responder cells without Th17 cells were performed under identical conditions. Activation of responder cells was induced by IL-2 (30 IU/ml) and Dynabeads Human T Activator CD3/CD28 (bead/cell ratio, 1:2). Responder cell IFN- $\gamma$ and IL-17 production in the absence or presence of Th17 cells was determined by intracellular cytokine staining after 4 days of coculture.

\section{Malachite green assay}

A malachite green assay was performed as previously described (51). The concentration of free phosphate was measured in the supernatant of Th17 cell cultures using the colorimetric Sensolyte Malachite Green Phosphate Assay kit (AnaSpec). Cells were washed in saline solution containing $0.9 \% \mathrm{w} / \mathrm{v} \mathrm{NaCl}$ and then exposed to $10 \mu \mathrm{M}$ ATP (Sigma-Aldrich) for 15 minutes. Phosphate concentration was then quantified at $600 \mathrm{~nm}$ using an absorbance plate reader upon comparison with a standard curve.

\section{TLC}

TLC was performed as previously described (18). Untreated or UCB-treated $3 \times 10^{5} \mathrm{Th} 17$ cells were incubated with $2 \mathrm{mCi} / \mathrm{ml}\left[\mathrm{C}^{14}\right] \mathrm{ADP}$ (GE Healthcare Life Sciences) in $10 \mathrm{mM} \mathrm{Ca}^{2+}$ and $5 \mathrm{mM} \mathrm{Mg}^{2+}$. [C $\left.\mathrm{C}^{14}\right]$-labeled ADP, AMP, and adenosine served as standards. TLC band density was examined using ImageJ software (NIH).

\section{Immunoblot analysis}

Immunoblot analysis was carried out as previously published (18), using $3.5 \times 10^{5}$ to $5 \times 10^{5}$ cells. Mouse anti-human ADA (Abcam, ab54969) primary Ab was applied at $1 \mu \mathrm{g} / \mathrm{ml}$. HRP-labeled goat anti-mouse secondary antibody (Thermo Scientific) was used at 1:50,000. Bands were visualized using Super Signal West Femto Sensitivity Substrate (Thermo Scientific) according to the manufacturer's instructions. For immunoblot normalization, the same samples were tested for the presence of $\beta$-actin using mouse antihuman $\beta$-actin (Abcam, ab8226) at 1:10,000 and, subsequently, HRP-labeled goat anti-mouse antibody at 1:20,000, as a secondary antibody. Band density was measured by ImageJ software. 


\section{Quantitative PCR}

Expression of human AHR, IL10, IL22, IL1B, HMOX1, FOXP3, and ENTPD1, and mouse Entpd1, Hmox1, and Cyp1a1 was determined by quantitative PCR (qPCR). Total RNA was extracted from $3 \times 10^{5}$ cells using TRIzol reagent (Thermo Scientific) and mRNA was reverse transcribed using an iScript cDNA Synthesis kit (Bio-Rad Laboratories) according to the manufacturer's instructions. Primer sequences of human $A H R$, HMOX1, and FOXP3 and of mouse Hmox1 and Cyp1A1 were as previously described (52-56). Human IL10 and ENTPD1 primer sequences were as follows: IL10 Forward 5'-TCCTTGCTGGAGGACTTTAAGGGT-3' and Reverse 5'-TGTCTGGGTCTTGGTTCTCAGCTT-3'; ENTPD1 Forward 5'-AGGTGCCTATGGCTGGATTAC-3' and Reverse 5'-CCAAAGCTCCAAAGGTTTCCT-3'.

PCR amplification conditions were as previously reported $(18,53)$. Expression of human $I L 22, I L 1 B$, and mouse Entpd1 was determined using TaqMan probes (Thermo Scientific). Samples were run on a Stratagene MX300SP (Agilent Technologies) and results were analyzed by matched software and expressed as relative quantification. Relative gene expression was determined after normalization to human and mouse $\beta$-actin and GAPDH

\section{Statistics}

Results are expressed as mean \pm SEM. Paired and unpaired Student's $t$ test ( 2 tailed) were used for comparing normally distributed data. One-way ANOVA followed by Tukey's multiple comparisons tests was used to compare means of multiple samples. For all comparisons, $P$ less than 0.05 was considered significant. Statistical analysis was performed using SPSS version 22.

\section{Study approval}

Animal care and experiments were conducted under the guidelines and protocols approved by the Animal Care and Use Committee, Beth Israel Deaconess Medical Center.

Human studies received IRB approval (2011P000202). Written consent was obtained from all study participants prior to inclusion in the study.

\section{Author contributions}

MSL, FJQ, and SCR conceived and designed the study. MSL performed and analyzed the experiments. MV, AK, JEK, AY, EC, BV, LF, and SM performed part of the experiments. MSL and SCR wrote the manuscript. BW, LO, AM, and FJQ reviewed the manuscript. MSL, AM, FJQ, and SCR obtained funding.

\section{Acknowledgments}

The authors wish to thank Efi Kokkotou for technical support and advice. This work has been supported by NIH grants R01 DK108894 (M.S.L.), P01 HL107152 and R21 CA164970 (S.C.R.), AI075285 and AI093903 (F.J.Q.) and by a Helmsley Charitable Trust grant 281574.5069091 .0010 (S.C.R. and A.M.).

Address correspondence to: Simon C. Robson or Maria Serena Longhi, Beth Israel Deaconess Medical Center, Gastroenterology, 330 Brookline Avenue, E/CLS 612 (S.C. Robson), or E/CLS 601 (M.S. Longhi) Boston, Massachusetts 02215, USA. Phone: 617.735.2921; E-mail: srobson@bidmc.harvard.edu (S.C. Robson). Phone: 617.735.2905; E-mail: mlonghi@bidmc.harvard.edu (M.S. Longhi).

1. Brites D. The evolving landscape of neurotoxicity by unconjugated bilirubin: role of glial cells and inflammation. Front Pharmacol. 2012;3:88

2. Liu Y, et al. Bilirubin possesses powerful immunomodulatory activity and suppresses experimental autoimmune encephalomyelitis. J Immunol. 2008;181(3):1887-1897.

3. Wu J, Ma J, Fan ST, Schlitt HJ, Tsui TY. Bilirubin derived from heme degradation suppresses MHC class II expression in endothelial cells. Biochem Biophys Res Commun. 2005;338(2):890-896.

4. Haga Y, Tempero MA, Kay D, Zetterman RK. Intracellular accumulation of unconjugated bilirubin inhibits phytohemagglutininduced proliferation and interleukin-2 production of human lymphocytes. Dig Dis Sci. 1996;41(7):1468-1474

5. Rocuts F, et al. Bilirubin promotes de novo generation of T regulatory cells. Cell Transplant. 2010;19(4):443-451.

6. Lee SS, et al. Heme oxygenase-1, carbon monoxide, and bilirubin induce tolerance in recipients toward islet allografts by modulating T regulatory cells. FASEB J. 2007;21(13):3450-3457.

7. Wang H, et al. Bilirubin can induce tolerance to islet allografts. Endocrinology. 2006;147(2):762-768

8. Zucker SD, et al. Bilirubin prevents acute DSS-induced colitis by inhibiting leukocyte infiltration and suppressing upregulation of inducible nitric oxide synthase. Am J Physiol Gastrointest Liver Physiol. 2015;309(10):G841-G854. 
9. Jangi S, Otterbein L, Robson S. The molecular basis for the immunomodulatory activities of unconjugated bilirubin. Int J Biochem Cell Biol. 2013;45(12):2843-2851.

10. Papatheodoridis GV, Hamilton M, Mistry PK, Davidson B, Rolles K, Burroughs AK. Ulcerative colitis has an aggressive course after orthotopic liver transplantation for primary sclerosing cholangitis. Gut. 1998;43(5):639-644.

11. de Vries HS, Te Morsche RH, Jenniskens K, Peters WH, de Jong DJ. A functional polymorphism in UGT1A1 related to hyperbilirubinemia is associated with a decreased risk for Crohn's disease. J Crohns Colitis. 2012;6(5):597-602.

12. Lenínek M, et al. The relationship between serum bilirubin and Crohn's disease. Inflamm Bowel Dis. 2014;20(3):481-487.

13. Vitek L, Zadinovà M, Stritesky J, Novotny L, Haluzik M. Amelioration of DSS-induced colitis in hyperbilirubinemic Gunn rats. J Crohn's Colitis. 2008;2(1):68.

14. Miossec P, Korn T, Kuchroo VK. Interleukin-17 and type 17 helper T cells. N Engl J Med. 2009;361(9):888-898.

15. Fujino S, et al. Increased expression of interleukin 17 in inflammatory bowel disease. Gut. 2003;52(1):65-70.

16. Atarashi K, et al. ATP drives lamina propria T(H)17 cell differentiation. Nature. 2008;455(7214):808-812.

17. Deaglio S, Robson SC. Ectonucleotidases as regulators of purinergic signaling in thrombosis, inflammation, and immunity. Adv Pharmacol. 2011;61:301-332.

18. Longhi MS, et al. Characterization of human CD39+ Th17 cells with suppressor activity and modulation in inflammatory bowel disease. PLoS One. 2014;9(2):e87956.

19. Kewley RJ, Whitelaw ML, Chapman-Smith A. The mammalian basic helix-loop-helix/PAS family of transcriptional regulators. Int J Biochem Cell Biol. 2004;36(2):189-204.

20. Schmidt JV, Bradfield CA. Ah receptor signaling pathways. Annu Rev Cell Dev Biol. 1996;12:55-89.

21. Quintana FJ, et al. Control of $\mathrm{T}(\mathrm{reg})$ and $\mathrm{T}(\mathrm{H}) 17$ cell differentiation by the aryl hydrocarbon receptor. Nature. 2008;453(7191):65-71.

22. Veldhoen M, et al. The aryl hydrocarbon receptor links TH17-cell-mediated autoimmunity to environmental toxins. Nature. 2008;453(7191):106-109.

23. Rohlman D, Pham D, Yu Z, Steppan LB, Kerkvliet NI. Aryl hydrocarbon receptor-mediated perturbations in gene expression during early stages of CD4(+) T-cell differentiation. Front Immunol. 2012;3:223.

24. Gandhi R, et al. Activation of the aryl hydrocarbon receptor induces human type 1 regulatory T cell-like and Foxp3(+) regulatory T cells. Nat Immunol. 2010;11(9):846-853.

25. Monteleone I, et al. Aryl hydrocarbon receptor-induced signals up-regulate IL-22 production and inhibit inflammation in the gastrointestinal tract. Gastroenterology. 2011;141(1):237-248, 248.e1.

26. Singh NP, Singh UP, Singh B, Price RL, Nagarkatti M, Nagarkatti PS. Activation of aryl hydrocarbon receptor (AhR) leads to reciprocal epigenetic regulation of FoxP3 and IL-17 expression and amelioration of experimental colitis. PLoS One. 2011;6(8):e23522.

27. Islam J, et al. Dietary tryptophan alleviates dextran sodium sulfate-induced colitis through aryl hydrocarbon receptor in mice. J Nutr Biochem. 2017;42:43-50.

28. Yeste A, et al. IL-21 induces IL-22 production in CD4 ${ }^{+}$T cells. Nat Commun. 2014;5:3753.

29. Zhong W, et al. Hemin exerts multiple protective mechanisms and attenuates dextran sulfate sodium-induced colitis. $J$ Pediatr Gastroenterol Nutr. 2010;50(2):132-139.

30. Piechota-Polanczyk A, Zielińska M, Piekielny D, Fichna J. The influence of lipoic acid on caveolin-1-regulated antioxidative enzymes in the mouse model of acute ulcerative colitis. Biomed Pharmacother. 2016;84:470-475.

31. Zhang L, Zhang Y, Zhong W, Di C, Lin X, Xia Z. Heme oxygenase-1 ameliorates dextran sulfate sodium-induced acute murine colitis by regulating Th17/Treg cell balance. J Biol Chem. 2014;289(39):26847-26858.

32. Meng L, et al. The Notch ligand DLL4 defines a capability of human dendritic cells in regulating Th1 and Th17 differentiation. J Immunol. 2016;196(3):1070-1080.

33. Ono Y, et al. T-helper 17 and interleukin-17-producing lymphoid tissue inducer-like cells make different contributions to colitis in mice. Gastroenterology. 2012;143(5):1288-1297.

34. Jiang W, et al. Elevated levels of Th17 cells and Th17-related cytokines are associated with disease activity in patients with inflammatory bowel disease. Inflamm Res. 2014;63(11):943-950.

35. Nielsen OH, Kirman I, Rüdiger N, Hendel J, Vainer B. Upregulation of interleukin-12 and -17 in active inflammatory bowe disease. Scand J Gastroenterol. 2003;38(2):180-185.

36. Seiderer J, et al. Role of the novel Th17 cytokine IL-17F in inflammatory bowel disease (IBD): upregulated colonic IL$17 \mathrm{~F}$ expression in active Crohn's disease and analysis of the IL17F p.His161Arg polymorphism in IBD. Inflamm Bowel Dis. 2008;14(4):437-445.

37. Chalmin F, et al. Stat 3 and Gfi-1 transcription factors control Th17 cell immunosuppressive activity via the regulation of ectonucleotidase expression. Immunity. 2012;36(3):362-373

38. Mascanfroni ID, et al. IL-27 acts on DCs to suppress the T cell response and autoimmunity by inducing expression of the immunoregulatory molecule CD39. Nat Immunol. 2013;14(10):1054-1063.

39. Veldhoen M, Hirota K, Christensen J, O'Garra A, Stockinger B. Natural agonists for aryl hydrocarbon receptor in culture medium are essential for optimal differentiation of Th17 T cells. J Exp Med. 2009;206(1):43-49.

40. Lee Y, et al. Induction and molecular signature of pathogenic TH17 cells. Nat Immunol. 2012;13(10):991-999.

41. Mascanfroni ID, et al. Metabolic control of type 1 regulatory T cell differentiation by AHR and HIF1- $\alpha$. Nat Med. 2015;21(6):638-646.

42. Phelan D, Winter GM, Rogers WJ, Lam JC, Denison MS. Activation of the Ah receptor signal transduction pathway by bilirubin and biliverdin. Arch Biochem Biophys. 1998;357(1):155-163.

43. Sinal CJ, Bend JR. Aryl hydrocarbon receptor-dependent induction of cyp1a1 by bilirubin in mouse hepatoma hepa 1c1c7 cells. Mol Pharmacol. 1997;52(4):590-599.

44. Baudiß K, et al. C1P attenuates lipopolysaccharide-induced acute lung injury by preventing NF- $\mathrm{KB}$ activation in neutrophils. J Immunol. 2016;196(5):2319-2326.

45. Esplugues E, et al. Control of TH17 cells occurs in the small intestine. Nature. 2011;475(7357):514-518. 
46. Idelman G, Smith DL, Zucker SD. Bilirubin inhibits the up-regulation of inducible nitric oxide synthase by scavenging reactive oxygen species generated by the toll-like receptor 4-dependent activation of NADPH oxidase. Redox Biol. 2015;5:398-408.

47. Enjyoji K, et al. Targeted disruption of cd39/ATP diphosphohydrolase results in disordered hemostasis and thromboregulation. Nat Med. 1999;5(9):1010-1017.

48. Friedman DJ, et al. From the cover: CD39 deletion exacerbates experimental murine colitis and human polymorphisms increase susceptibility to inflammatory bowel disease. Proc Natl Acad Sci USA. 2009;106(39):16788-16793.

49. Wirtz S, Neufert C, Weigmann B, Neurath MF. Chemically induced mouse models of intestinal inflammation. Nat Protoc. 2007;2(3):541-546.

50. Mimran A, et al. DNA vaccination with CD25 protects rats from adjuvant arthritis and induces an antiergotypic response. $J C l i n$ Invest. 2004;113(6):924-32.

51. Grant CR, et al. Dysfunctional CD39(POS) regulatory T cells and aberrant control of T-helper type 17 cells in autoimmune hepatitis. Hepatology. 2014;59(3):1007-1015.

52. Zhu J, et al. Increased expression of aryl hydrocarbon receptor and interleukin 22 in patients with allergic asthma. Asian Pac $J$ Allergy Immunol. 2011;29(3):266-272.

53. Amara IE, Anwar-Mohamed A, Abdelhamid G, El-Kadi AO. Effect of mercury on aryl hydrocarbon receptor-regulated genes in the extrahepatic tissues of C57BL/6 mice. Food Chem Toxicol. 2012;50(7):2325-2334.

54. Schallner N, et al. Microglia regulate blood clearance in subarachnoid hemorrhage by heme oxygenase-1. J Clin Invest. 2015;125(7):2609-2625.

55. Wegiel B, et al. Macrophages sense and kill bacteria through carbon monoxide-dependent inflammasome activation. J Clin Invest. 2014;124(11):4926-4940.

56. Longhi MS, et al. Effect of $\mathrm{CD} 4{ }^{+} \mathrm{CD} 25^{+}$regulatory T-cells on $\mathrm{CD} 8 \mathrm{~T}$-cell function in patients with autoimmune hepatitis J Autoimmun. 2005;25(1):63-71. 